\title{
URG4/URGCP enhances the angiogenic capacity of human hepatocellular carcinoma cells in vitro via activation of the NF-KB signaling pathway
}

Sizhong Xing ${ }^{1,2,3 \dagger}{ }^{+}$Bing Zhang ${ }^{4 \dagger}$, Ruixi Hua ${ }^{5+}{ }^{+}$William Chi-shing Tai ${ }^{6}$, Zhirong Zeng ${ }^{2}$, Binhui Xie ${ }^{7}$, Chenghui Huang $^{3}$, Jisu Xue ${ }^{3}$, Shiqiu Xiong ${ }^{8}$, Jianyong Yang ${ }^{4^{*}}$, Side Liu ${ }^{1 *}$ and Heping Li $i^{4,5^{*}}$

\begin{abstract}
Background: Angiogenesis is essential for tumor growth. Hepatocellular carcinoma (HCC) is characterized by hypervascularity; high levels of angiogenesis are associated with poor prognosis and a highly invasive phenotype in HCC. Up-regulated gene-4 (URG4), also known as upregulator of cell proliferation (URGCP), is overexpressed in multiple tumor types and has been suggested to act as an oncogene. This study aimed to elucidate the effect of URG4/URGCP on the angiogenic capacity of HCC cells in vitro.

Methods: Expression of URG4/URGCP in HCC cell lines and normal liver epithelial cell lines was examined by Western blotting and quantitative real-time PCR. URG4/URGCP was stably overexpressed or transiently knocked down using a shRNA in two HCC cell lines. The human umbilical vein endothelial cell (HUVEC) tubule formation and Transwell migration assays and chicken chorioallantoic membrane (CAM) assay were used to examine the angiogenic capacity of conditioned media from URG4/URGCP-overexpressing and knockdown cells. A luciferase reporter assay was used to examine the transcriptional activity of nuclear factor kappa - light - chain - enhancer of activated B cells (NF-kB). NF-kB was inhibited by overexpressing degradation-resistant mutant inhibitor of $\mathrm{kB}$ (I $\mathrm{KB}$ )-a. Expression of vascular endothelial growth factor $\mathrm{C}$ (VEGFC), tumor necrosis factor-a (TNFa), interleukin (IL)-6, IL-8 and v-myc avian myelocytomatosis viral oncogene homolog (MYC) were examined by quantitative real-time PCR; VEGFC protein expression was analyzed using an ELISA.
\end{abstract}

Results: URG4/URGCP protein and mRNA expression were significantly upregulated in HCC cell lines. Overexpressing URG4/URGCP enhanced - while silencing URG4/URGCP decreased - the capacity of HCC cell conditioned media to induce HUVEC tubule formation and migration and neovascularization in the CAM assay. Furthermore, overexpressing URG4/URGCP increased - whereas knockdown of URG4/URGCP decreased - VEGFC expression, NF-kB transcriptional activity, the levels of phosphorylated (but not total) IKB kinase (IKK) and IKB-a, and expression of TNFa, IL-6, IL-8 and MYC in HCC cells. Additionally, inhibition of NF-KB activity in HCC cells abrogated URG4/URGCP-induced NF-KB activation and angiogenic capacity.

Conclusions: This study suggests that URG4/URGCP plays an important pro-angiogenic role in HCC via a mechanism linked to activation of the NF-KB pathway; URG4/URGCP may represent a potential target for anti-angiogenic therapy in HCC.

Keywords: URG4/URGCP, Hepatocellular carcinoma, Angiogenesis

\footnotetext{
* Correspondence: jianyongyang0899@hotmail.com; side743@126.com;

Full list of author information is available at the end of the article
} 


\section{Background}

Angiogenesis, the formation of new blood vessels, occurs during numerous physiological and pathological processes [1]. Angiogenesis is required to maintain tumor growth and metastasis, and constitutes an important hallmark of tumor progression [2-5]. Tumor angiogenesis is the generation of a network of blood vessels that penetrates into the tumor to supply the nutrients and oxygen required to maintain and enable tumor growth and invasion. Consequently, blocking tumor angiogenesis could prevent the formation of tumor blood vessels and inhibit or slow the growth and spread of tumor cells [6-8]. Angiogenesis is widely regarded to be an effective therapeutic target and promising biomarker for the diagnosis of cancer; therefore, angiogenesis is an important field of research in biological and clinical oncology [9-13]. Tumor angiogenesis is a consequence of an imbalance between pro-angiogenic factors, such as the vascular endothelial growth factor (VEGF) family and IL-8/ CXCL8, and inhibitors of angiogenesis, including endostatin, angiostatin and other related molecules [14-16]. VEGF regulates the sprouting and proliferation of endothelial cells and can stimulate tumor angiogenesis [17]. A number of currently-used anti-angiogenesis drugs function by inhibiting pro-angiogenic factors, for example the monoclonal antibody bevacizumab binds to VEGF and prevents it from binding to the VEGF receptors, and sunitinib and sorafenib are small molecules that attach to VEGF-R and inhibit the binding of VEGF $[18,19]$. However, the precise regulation and mechanisms of tumor angiogenesis are not yet fully explored and the identification of other novel specific, effective inhibitors of angiogenesis is urgently required to treat patients with cancer.

Hepatocellular carcinoma (HCC) accounts for $90 \%$ of all primary malignant liver cancers and is the fifth most common cancer and third most common cause of cancer-related mortality worldwide [20,21]. HCC has a much higher morbidity in Asia due to the high incidence of hepatitis B virus (HBV) and hepatitis $\mathrm{C}$ virus (HCV) infection, especially in China where $55 \%$ of all cases of HCC worldwide occur [21]. HCC is characterized by hypervascularity indicative of angiogenesis, and tumor growth in HCC relies on the formation of new blood vessels [15]. VEGF has been reported to a play critical role in angiogenesis in HCC [22]. Targeting angiogenesis using pharmacologic strategies has recently been validated in several other solid tumor types [23]. Therefore, identification of an anti-angiogenic strategy for HCC may help to improve the treatment outcomes and extend survival for patients with HCC.

Up-regulated gene-4 (URG4), also known as upregulator of cell proliferation (URGCP), is located on chromosome $7 \mathrm{p} 13$ and was identified and initially characterized by Tufan et al. URG4/URGCP is upregulated in the presence of hepatitis $\mathrm{B}$ virus $\mathrm{X}$ antigen $(\mathrm{HBxAg})$ and contributes to the development of HCC as it can promote hepatocellular growth and survival both in vitro and in vivo [24]. Previous studies demonstrated that URG4/URGCP is upregulated in human HCC and gastric cancer and URG4/URGCP could promote the proliferation and tumorigenicity of $\mathrm{HCC}$ and gastric cancer cells $[25,26]$. Based on these findings, URG4/URGCP has been suggested to function as an oncogene in multiple tumor types [25-28]. However, the effect of URG4/URGCP on tumor angiogenesis in $\mathrm{HCC}$ has not yet been elucidated.

In the present study, we demonstrate that URG4/ URGCP is upregulated in HCC cell lines. Additionally, ectopic overexpression of URG4/URGCP enhanced the angiogenic capacity of HCC cells in vitro and also upregulated VEGF and activated the NF- $\mathrm{kB}$ signaling pathway, whereas knockdown of URG4/URGCP had the opposite effects. This study demonstrates that URG4/URGCP may promote angiogenesis and the expression of VEGF$\mathrm{C}$ in $\mathrm{HCC}$ by activating the NF- $\mathrm{kB}$ signaling pathway; therefore, URG4/URGCP may have potential as a therapeutic target in HCC.

\section{Methods}

\section{Cells and treatments}

The normal liver epithelial cell lines Lo2 and THLE3 were purchased from and cultured as recommended by the American Type Culture Collection (Manassas, VA, USA). The HCC cell lines Hep3B, MHCC97H, HepG2, SMMC-7721, QGY-7703, Huh7 and BEL-7402 were purchased from the ATCC and cultured in Dulbecco's modified Eagle's medium (DMEM; Invitrogen, Carlsbad, CA, USA) supplemented with $10 \%$ fetal bovine serum (FBS) and $100 \mathrm{U}$ penicillin-streptomycin (Invitrogen) in a humidified incubator at $37^{\circ} \mathrm{C}$ in $5 \% \mathrm{CO}_{2}$.

\section{Vectors, retrovirus infection and transfection}

The URG4/URGCP expression construct was generated by sub-cloning PCR-amplified full-length human URG4/ $U R G C P$ cDNA into pMSCV-retro-puro (Promega, Madison, WI, USA) using the forward primer 5 '-CCAGATCTAC CATGG CGTCGCCCGGGCATTC-3' and reverse primer 5'-GCCGAATTCTCACAGC CGTCTCACCAGCT-3'.

To knockdown URG4/URGCP, a siRNA sequence targeting human URG4/URGCP (5'-ACCAAAGACTTG CCCTGGAATT-3'; synthesized by Invitrogen) was cloned into pSuper-retro-puro (Promega) to generate pSuperretro-URG4/URGCP-RNAi (referred to as URG4-Ri) [26]. Retrovirus generation and infection were performed as described previously [29].

The vector pBabe-Puro-IкB $\alpha$-mut, which expresses degradation-resistant IкB $\alpha$ mutant protein (referred to as ІкB $\alpha$-mut), was purchased from Addgene (plasmid 15291; Cambridge, MA, USA) and used as a NF-кB 
inhibitor. The HCC cells were transiently transfected with pBabe-Puro-ІкB $\alpha$-mut using Lipofectamine 2000 reagent (Invitrogen) according the manufacturer's instructions.

\section{Quantitative real-time RT-PCR}

Total cellular RNA was extracted using TRIzol reagent (Invitrogen) and $2 \mu \mathrm{g}$ of RNA was subjected to cDNA synthesis using random hexamers. Quantitative realtime RT-PCR (qRT-PCR) was performed using an Applied Biosystems 7500 Sequence Detection system with an initial denaturation step at $95^{\circ} \mathrm{C}$ for $10 \mathrm{~min}$, followed by 28 cycles of denaturation at $95^{\circ} \mathrm{C}$ for $60 \mathrm{sec}$, primer annealing at $58^{\circ} \mathrm{C}$ for $30 \mathrm{sec}$ and primer extension at $72^{\circ} \mathrm{C}$ for $30 \mathrm{sec}$, with a final extension step at $72^{\circ} \mathrm{C}$ for $5 \mathrm{~min}$. Target gene expression was calculated using the threshold cycle $(\mathrm{Ct})$ values and the formula $2^{-[(\mathrm{Ct}}$ of Genes) - (Ct of GAPDH)] relative to the internal control gene GAPDH. PCR primers were designed using Primer Express version 2.0 (Applied Biosystems, Foster City, CA, USA) and were as follows: VEGFC forward: 5' -GTGTCCAGTGTAGATGAACTC-3' and reverse: 5 '-ATCTGTAGACGGACACACATG-3'; TNF $\alpha$ forward: 5'-CCAGGCAGTCAGATCATCTTCTC-3' and reverse: 5'-AGCTGGTTATCTCTCAGCTCCAC-3'; IL-6 forward: 5' -TCTCCACAAGCGCCTTCG-3' and 5' -CTC AGGGCTGAGATGCCG; $I L-8$ forward: 5'-TGCCAAG GAGTGCTAAAG-3' and reverse: 5'-CTCCACAACCC TCTGCAC-3'; MYC forward: 5'-TCAAGAGGCGAA CACACAAC-3' and reverse: 5'-GGCCTTTTCATTGT TTTCCA-3'; GAPDH forward: 5'-ATTCCACCCATGG CAAATTC-3' and reverse: 5'-AGAGGCAGGGATGA TGTTCTG-3'.

\section{Western blotting}

Total cellular protein was extracted and the samples were heated at $100^{\circ} \mathrm{C}$ for $5 \mathrm{~min}$. Samples containing $20 \mu \mathrm{g}$ protein were separated by SDS-PAGE, electroblotted onto PVDF membranes (Millipore, Billerica, MA, USA), blocked in non-fat milk, probed with polyclonal rabbit anti-URG4 (Abcam, Cambridge, MA, USA), anti-IKK, anti-phosphorylated-IKK (p-IKK), anti-

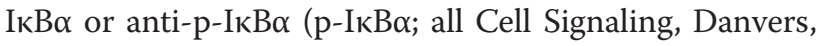
MA, USA). The membranes were stripped and reprobed using anti- $\alpha$-Tubulin (Cell Signaling) as a loading control.

\section{HUVEC tubule formation assay}

The HUVEC tubule formation assay was performed as previously reported [23]. Briefly, $200 \mu \mathrm{l}$ Matrigel was placed into each well of a 24-well plate and polymerized for $30 \mathrm{~min}$ at $37^{\circ} \mathrm{C}$. HUVECs (approximately $2 \times 10^{4}$ ) in $200 \mu \mathrm{l}$ conditioned media (CM) from indicated HCC cells were added to each well and incubated for $24 \mathrm{~h}$ at $37^{\circ} \mathrm{C}$ in $5 \% \mathrm{CO}_{2}$. Images were captured at $100 \times$ using a bright-field microscope, and formation of capillary tubes was quantified by measuring their total length of each image.

\section{Chicken chorioallantoic membrane assay}

The chicken chorioallantoic membrane (CAM) assay was performed using eight-day-old fertilized chicken eggs. A $1 \mathrm{~cm}$ diameter window was created in the shell of each egg and the surface of the dermic sheet was removed to expose the CAM. A $0.5 \mathrm{~cm}$ diameter filter paper was placed on top of the CAM, and $100 \mu \mathrm{l} C M$ harvested from the indicated HCC cells placed on the center of the filter paper. The eggs were incubated at $37^{\circ} \mathrm{C}$ at $80-90 \%$ relative humidity for $48 \mathrm{~h}$, then the windows in the shell were closed using sterilize bandages. Following fixation with stationary solution (1:1 $\mathrm{vol} / \mathrm{vol}$ mixture of methanol and acetone) for $15 \mathrm{~min}$, the CAM was excised and imaged using a digital camera. The number of second- and third-order vessels in the test groups was expressed relative to that of CAM treated with CM from the vector control cells.

\section{HUVEC transwell migration assay}

HUVECs (approximately $1 \times 10^{4}$ ) were plated on the top of polycarbonate Transwell filters (pore size $8.0 \mu \mathrm{m}$; Corning Incorporated, Corning, NY, USA ) in CM containing 5\% FBS. The lower chamber was filled with $500 \mu \mathrm{l}$ of media containing 15\% FBS. The cells were incubated at $37^{\circ} \mathrm{C}$ for about $20 \mathrm{~h}$, and the cells that migrated to the lower membrane surface were fixed in $4 \%$ paraformaldehyde, stained using hematoxylin for $15 \mathrm{~min}$, and the number of cells in ten randomlyselected 200x fields of view per filter was counted and expressed relative to that of cells treated with $\mathrm{CM}$ from vector control cells.

\section{Luciferase reporter assay of NF- $\mathrm{kB}$ transcriptional activity} The pNF-kB-luciferase reporter and control plasmids (Clontech, Mountain View, CA, USA) were used examine NF- $\mathrm{kB}$ transcriptional activity. Approximately $1.5 \times$ $10^{4} \mathrm{HCC}$ cells were seeded in triplicate in 24-well plates, allowed to adhere, and co-transfected with $100 \mathrm{ng}$ of the NF-KB luciferase reporter plasmid or control luciferase plasmid and $1 \mathrm{ng}$ of pRL-TK Renilla plasmid (Promega) using Lipofectamine 2000 reagent (Invitrogen). The luciferase and Renilla signals were measured $48 \mathrm{~h}$ after transfection using the Dual Luciferase Reporter Assay Kit (Promega) according to the manufacturer's protocol.

\section{Enzyme-linked immunosorbent assay}

The VEGFC enzyme-linked immunosorbent assay (ELISA) was performed using a commercial kit according to the manufacturer's instructions (Keygentec Co., Shanghai, China). Briefly, standard solutions, test samples and 
negative control samples were added to the plate in triplicate, incubated at $36^{\circ} \mathrm{C}$ for $90 \mathrm{~min}$, washed, incubated with a specific anti-VEGFC antibody (Cell Signaling) at $36^{\circ} \mathrm{C}$ for $1 \mathrm{~h}$, washed, incubated with secondary antibody from the kit for $1 \mathrm{~h}$, substrate was added, incubated for $1 \mathrm{~h}$ and the absorbance values were read at $\mathrm{OD}_{450}$ using an ELISA plate reader.

\section{Statistical analysis}

All experimental data are presented as the mean \pm SD of three independent biological replicates. Statistical analyses were performed using SPSS 13.0 (IBM, Armonk, NY, USA). Analysis of variance (ANOVA) was used to evaluate the significance of the differences between two groups. $P$-values $\leq 0.05$ were considered statistically significant.

\section{Results}

URG4/URGCP is upregulated in HCC cell lines

Western blotting and qRT-PCR analyses were performed to examine URG4/URGCP protein and mRNA expression in HCC cell lines. URGCP/URG4 protein expression was significantly upregulated in all seven HCC cell lines tested compared to two normal liver epithelial cell lines, Lo2 and THLE3, which expressed low or undetectable levels of URGCP/URG4 (Figure 1A). Consistent with the Western blotting analysis, qRT-PCR demonstrated that URG4/ URGCP mRNA was markedly upregulated in all seven HCC cell lines compared to the normal liver epithelial cell lines (Figure 1B). These data suggest that URG4/URGCP is upregulated in HCC cells.

\section{URG4/URGCP promotes the angiogenic capacity and expression of VEGFC in HCC cells}

The HCC cell lines QGY7703 and Hep3B expressed moderate levels of URG4/URGCP and were used to create stable cell lines overexpressing URG4/URGCP. Overexpression of URG4/URGCP in the stable cell lines was verified by Western blotting (Figure 2A).

Firstly, the effect of URG4/URGCP on the ability of $\mathrm{HCC}$ cells to induce angiogenesis was investigated using
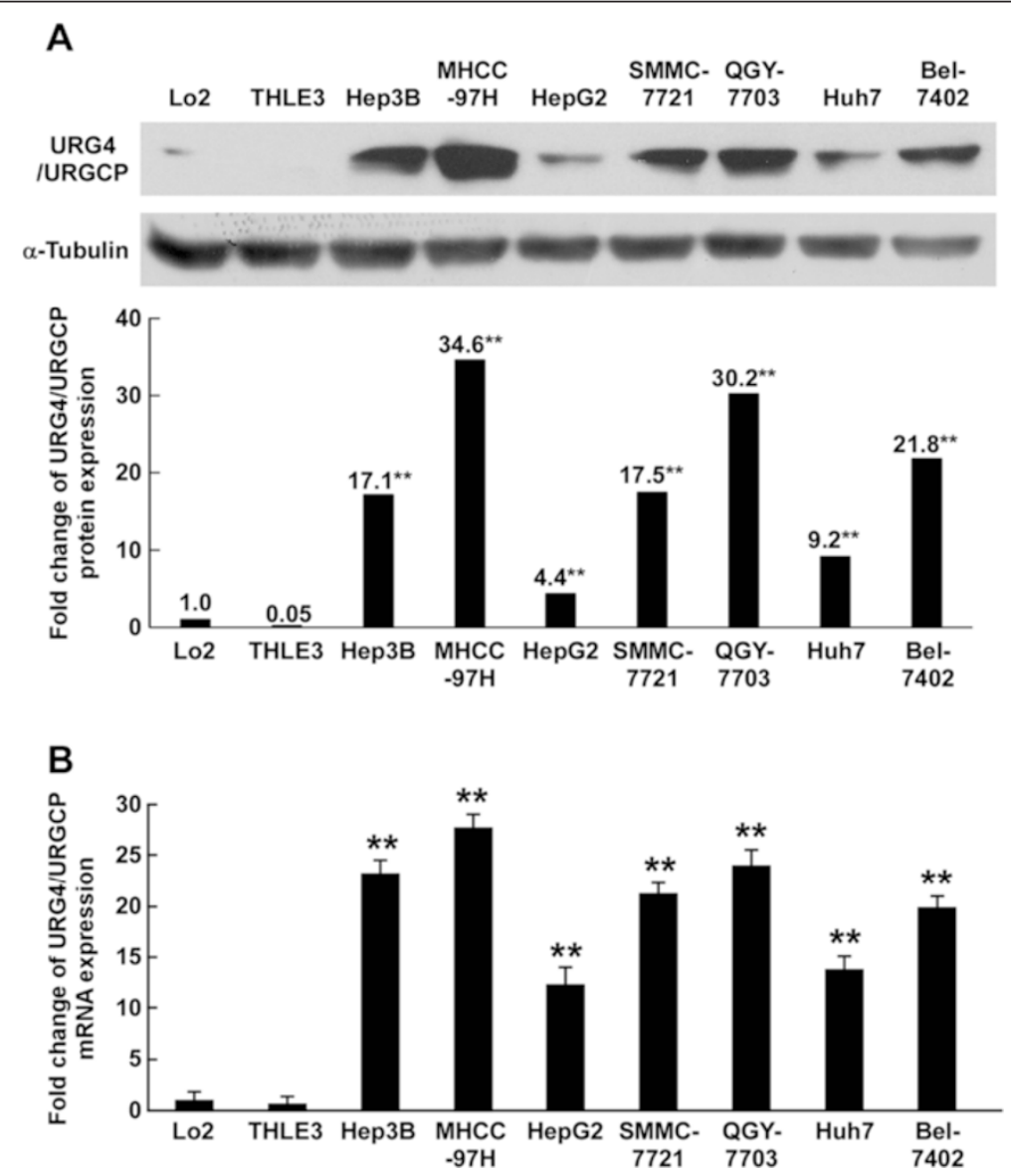

Figure 1 URG4/URGCP is upregulated in HCC cell lines. A. Western blotting analysis of URG4/URGCP protein expression in two normal liver cell lines and seven HCC cell lines; a-Tubulin was used as a loading control. Lower panel, quantification of Western blotting data relative to Lo2 cells. B. Real-time PCR quantification of URG4/URGCP mRNA expression in two normal liver cell lines and seven HCC cell lines. Transcript levels were normalized to GAPDH and expressed relative to Lo2 cells. Data is mean \pm SD of three independent experiments; ${ }^{* *} P<0.01$. 

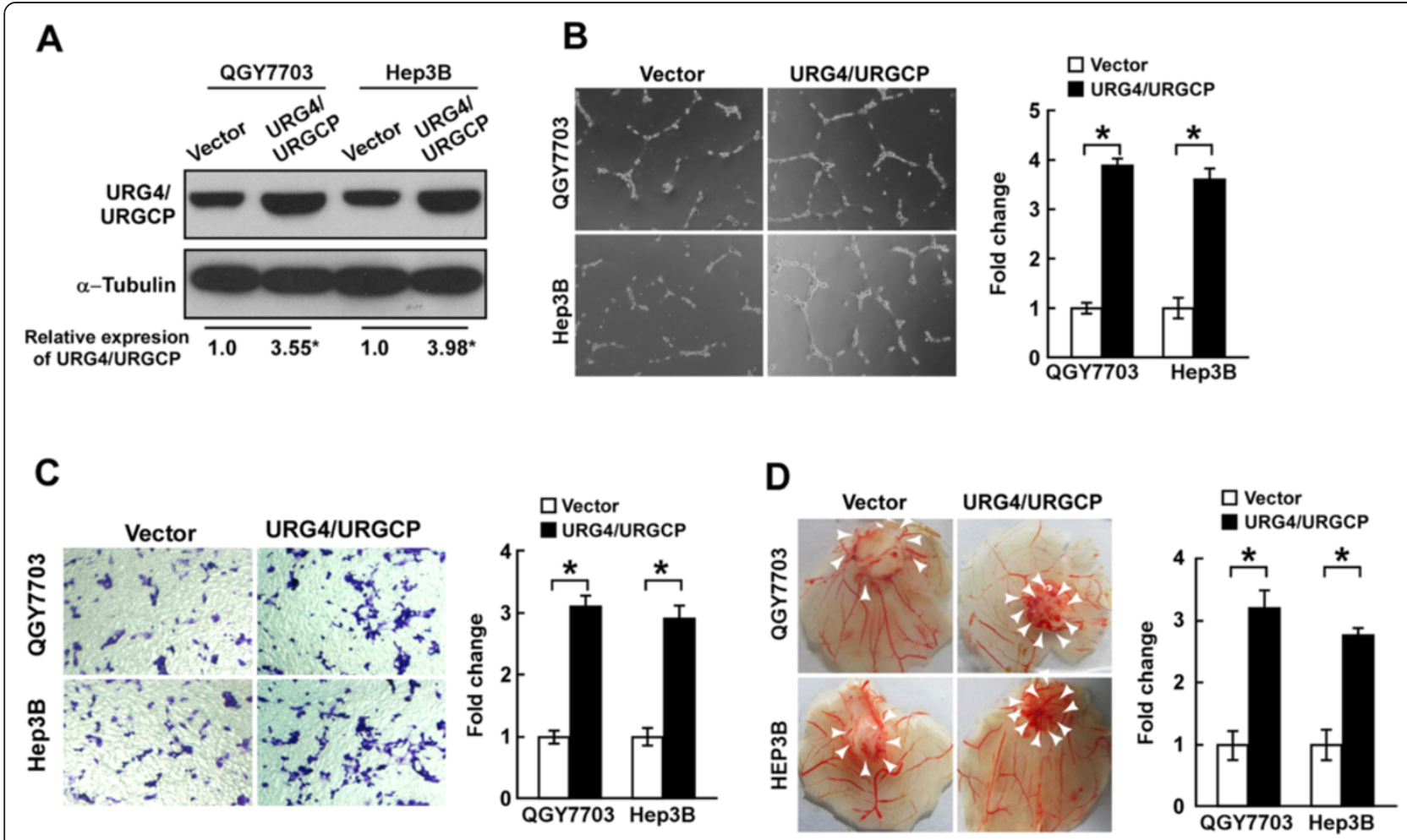

E
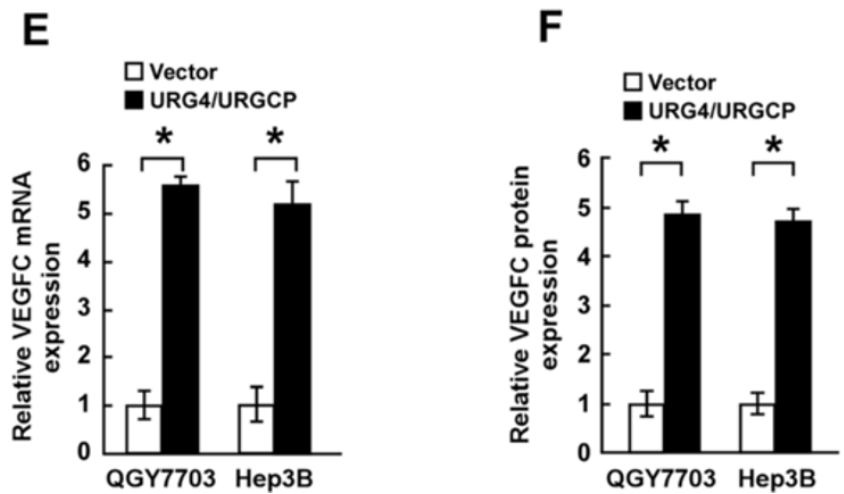

Figure 2 URG4/URGCP enhances the angiogenic capacity of HCC cells in vitro. A. Western blotting analysis of URG4/URGCP protein expression in QGY7703 - vector, QGY7703-URG4/URGCP, Hep3B-vector and Hep3B-URG4/URGCP cells; a-Tubulin was used as a loading control. The numbers represent the relative expression of each protein compared to the respective control cells. B. Representative images (left) and quantification (right) of tube-like structures formed by HUVECs on Matrigel-coated plates when cultured in conditioned medium (CM) derived from the indicated cells. C. Representative images (left) and quantification (right) of the number of migrated HUVEC cells after incubation in CM derived from the indicated cells in the Transwell migration assay. D. Representative images (left) and quantification (right) of neovessels formed in the CAM assay when stimulated by CM derived from the indicated cells. E. Quantitative real-time PCR analysis of VEGFC mRNA expression in the indicated cells. Transcript levels were normalized to GAPDH and expressed relative to the respective control cells. F. ELISA of VEGFC protein expression in the indicated cell supernatants. Data is mean \pm SD of three independent experiments; ${ }^{*} P<0.05$.

the HUVEC tubule formation assay. HUVECs were seeded on Matrigel in CM harvested from URG4/ URGCP-overexpressing HCC cells. CM derived from URG4/URGCP-transduced cells significantly increased the formation of tubule structures compared to $\mathrm{CM}$ from vector control cells (Figure 2B). Moreover, CM from URG4/URGCP-overexpressing HCC cells significantly increased the migration of HUVEC cells in the migration assay (Figure 2C). Furthermore, ectopic overexpression of URG4/URGCP in HCC cells enhanced the ability of CM to induce the formation of second- and third-order vessels in the CAM assay (Figure 2D).

As neovessel formation is closely associated with VEGFC, we examined the expression of VEGFC in 
URG4/URGCP-overexpressing and vector control HCC cells using qRT-PCR and an ELISA. VEGFC mRNA and protein expression were significantly upregulated in the URG4/URGCP-overexpressing HCC cells (Figure 2, E and F). However, the results were not repeated when these experiments were performed with Lo2 and THLE3 cells stably overexpressing URG4/URGCP (Additional file 1: Figure S1). Taken together, these results suggest that URG4/URGCP enhanced the capacity of HCC cells to induce neovessel formation in vitro.

\section{Silencing URG4/URGCP reduces the angiogenic capacity and expression of VEGFC in HCC cells}

To further confirm the effect of URG4/URGCP on angiogenesis during the progression of $\mathrm{HCC}$, stable QGY7703 and Hep3B cell lines in which URG4/URGCP was silenced were established; knockdown of URG4/ URGCP in these cells was confirmed by Western blotting (Figure 3A). Compared to CM from vector control cells, CM from URG4/URGCP-silenced cells inhibited tubule formation by HUVECs (Figure 3B), suggesting that knockdown of endogenous URG4/URGCP reduced the ability of HCC cells to promote angiogenesis. Moreover, CM from URG4/URGCP-silenced HCC cells inhibited HUVEC migration (Figure $3 \mathrm{C}$ ) and decreased the formation of second- and third-order vessels in the CAM assay (Figure 3D). In parallel with these results, knockdown of URG4/URGCP significantly reduced VEGFC mRNA and protein expression in both HCC cell lines (Figure 3E and F). These results confirmed that URG4/ URGCP enhances the angiogenic capacity of HCC cells.

\section{URG4/URGCP promotes the angiogenic capacity of HCC} cells via activating the NF-кB signaling pathway

As $V E G F C$ has been reported to be a downstream target of the NF- $\kappa B$ pathway [30-33], we explored effect of URG4/URGCP on NF- $\mathrm{BB}$ signaling activity. Luciferase reporter assays demonstrated that overexpression of URG4/URGCP enhanced the transcriptional activity of a NF-kB reporter gene, while knockdown of URG4/URGCP suppressed NF- $\mathrm{kB}$ transcriptional activity (Figure 4A). Western blotting showed that overexpression of URG4/ URGCP increased the levels of phosphorylated IKK and phosphorylated I $\mathrm{I} B \alpha$ but did not significantly change the total protein level of IKK or IKB $\alpha$ (Figure 4B). In addition, the levels of number of $N F-\kappa B$ target genes, including TNF- $\alpha, I L-6, I L-8$ and $M Y C$, were upregulated in URG4/URGCP-overexpressing cells and downregulated in URG4/URGCP-silenced HCC cells (Figure 4C). Taken together, these results indicated that the NF- $\mathrm{kB}$ pathway may underlie the pro-angiogenic effect of URG4/URGCP in HCC.
Inhibition of NF-KB signaling activity inhibits the ability of URG4/URGCP to enhance the angiogenic capacity of HCC cells

We further explored whether URG4/URGCP increased the angiogenic capacity of HCC cells by activating NF$\kappa \mathrm{B}$ signaling. NF- $\kappa \mathrm{B}$ signaling was inhibited by transient overexpression of a non-degradable $\mathrm{I} \kappa \mathrm{B} \alpha$ mutant containing alanine residues in positions 32 and 36 instead of serine residues, which cannot be phosphorylated and degraded [34] and thus remains bound to and inhibits NF$\kappa \mathrm{B}$. The stimulatory effects of CM derived from URG4/ URGCP-overexpressing HCC cells on HUVEC tubule formation and migration were significantly reversed when the I $\mathrm{K} B \alpha$ mutant was transiently overexpressed in the HCC cells (Figure 5, A-C; Additional file 2: Figure S2). Similar results were obtained in the CAM assay, as the $\mathrm{I} \kappa \mathrm{B} \alpha$ mutant reversed the ability of $\mathrm{CM}$ collected from URG4/URGCP-overexpressing $\mathrm{HCC}$ cells to promote angiogenesis (Figure 5D). Collectively, these data suggest that URG4/URGCP enhances the angiogenic capacity of $\mathrm{HCC}$ cells via a mechanism involving functional activation of the NF- $\mathrm{kB}$ signaling pathway.

\section{Discussion}

URG4/URGCP can promote the growth and survival of $\mathrm{HCC}$ cells and was the first gene identified to be upregulated in the presence of HBxAg [24], indicating URG4/ URGCP may potentially play a role in the progression of HCC. Besides its ability to promote HCC cell proliferation, the precise role of URG4/URGCP in HCC has not yet been elucidated [24,26]. In this study, we demonstrate for the first time that URG4/URGCP can enhance the angiogenic capacity of HCC cells in vitro; therefore, URG4/URGCP may exert a number of functions during the development and progression of HCC and should be considered as a potential novel therapeutic target for HCC. Besides the hepatocarcinogenesis function of URG4/URGCP, it has been reported that URG4/URGCP is also upregulated in gastric cancer tissues and cells and enhances gastric cancer cell proliferation and tumorigenesis [25]. High expression level of URG4 was also found in acute lymphoblastic leukemia (ALL) patients indicating that URG4 might be involved in leukemogenesis [35]. However, future studies are needed to demonstrate the exact role of URG4 in various malagnancies.

Although several studies have indicated that URG4/ URGCP may act as an oncogene in various tumor types [26,36-38], the exact function and molecular mechanism of actions of URG4/URGCP have not been precisely characterized. In the present study, we found that overexpression of URG4/URGCP increased the formation of tubule structures in HUVEC cells and significantly increased the migration of HUVEC cells in the migration assay, and enhanced the ability to induce the formation 


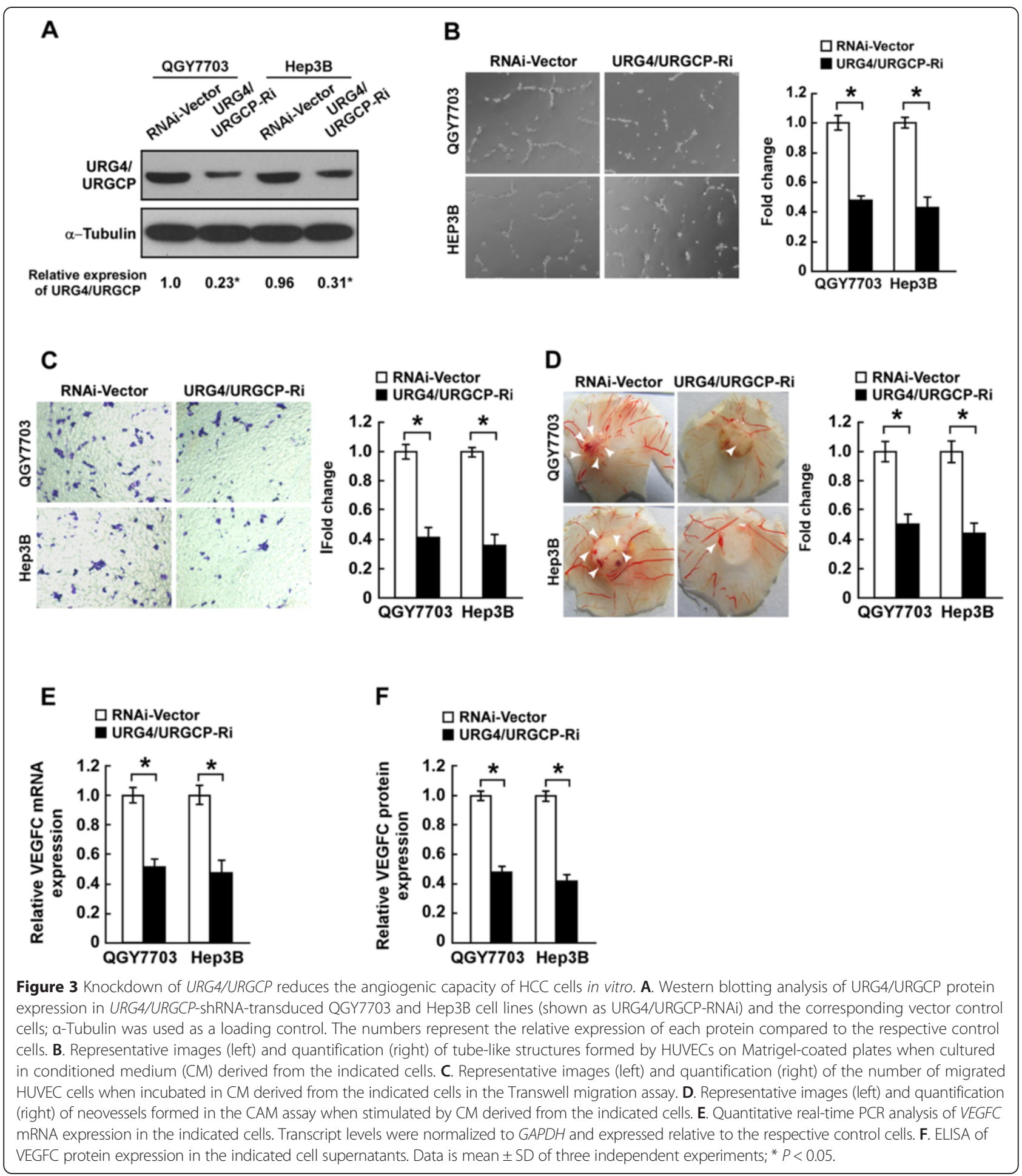

of second- and third-order vessels of CAM. All of the results indicate the promotive effect of URG4/URGCP in $\mathrm{HCC}$ angiogenic progression. In combination with the ability of URG4/URGCP to promote the angiogenic capacity of HCC cells, VEGFC was markedly upregulated in URG4/URGCP-overexpressing cells, indicating that an association exists between URG4/URGCP and VEGFC. $V E G F C$ is one of the target genes downstream of the NF-kB pathway [30-33]. Luciferase reporter assays showed overexpression of URG4/URGCP significantly enhanced the transcriptional activity of NF- $\mathrm{B}$, suggesting NF- $\mathrm{kB}$ plays an essential role in the URG4/URGCP- 

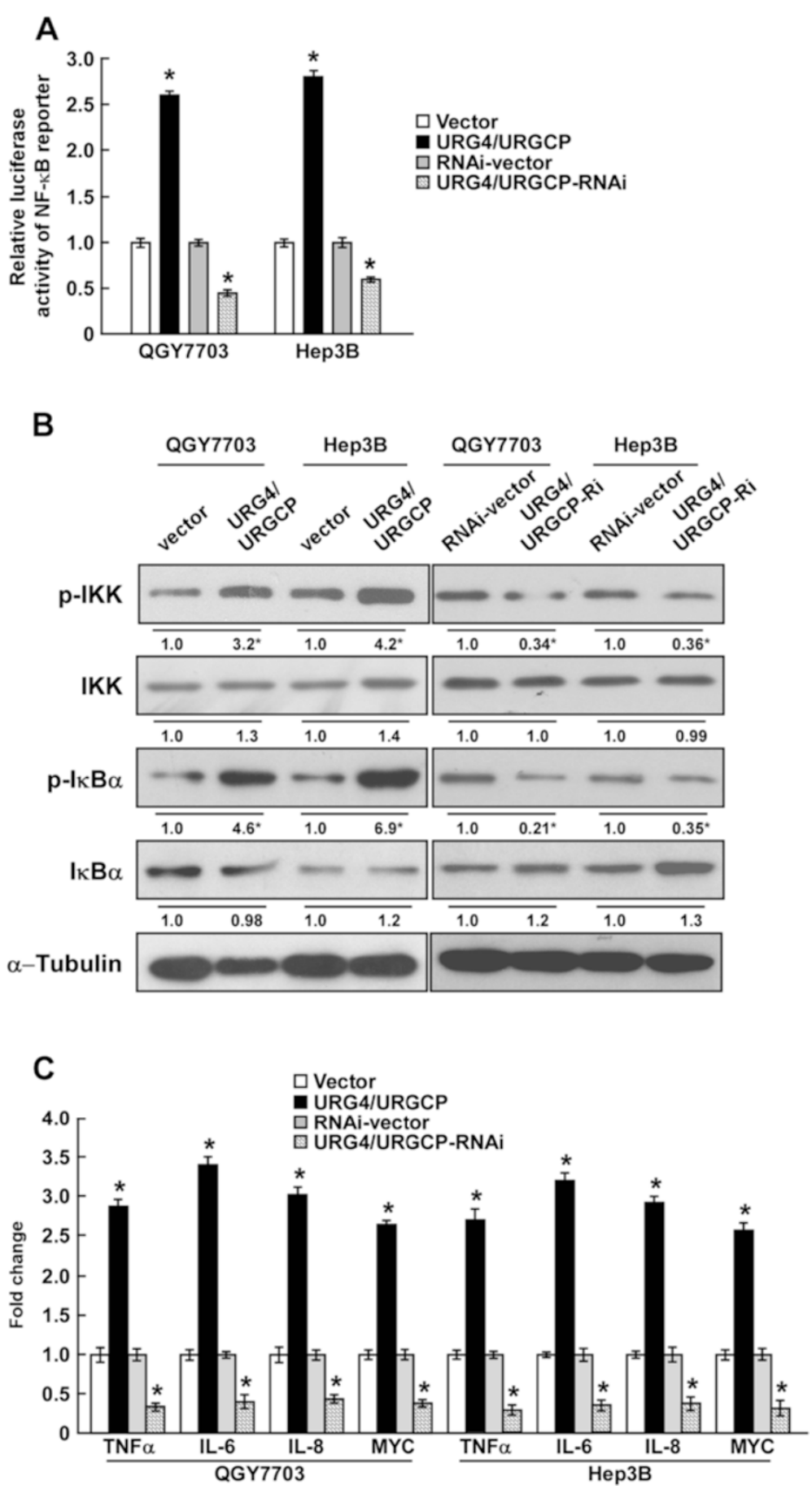

Figure 4 URG4/URGCP promotes NF-KB transcriptional activity. A. Luciferase reporter assay of NF-KB transcriptional activity in URG4/URGCP-overexpressing or silenced cells expressed relative to the respective control cells. B. Western blotting analysis of the expression of phosphorylated IKK $(\mathrm{p}-\mathrm{IKK})$, total IKK, phosphorylated IKBa $(\mathrm{p}-\mathrm{IKB})$ and total IKBa; $\mathrm{a}$-Tubulin was used as a loading control. The numbers represent the relative expression of each protein compared to the respective control cells. C. Quantitative real-time PCR analysis of the expression of genes downstream of NF-kB in the indicated cells; transcript levels were normalized to GAPDH and expressed relative to the respective vector control cells. Data is mean \pm SD of three independent experiments; ${ }^{*} P<0.05$.

induced angiogenic capacity of HCC cells. NF-kB has been widely studied as a transcription factor that regulates inflammatory and immune responses, as well as range of other physiological and pathological processes including the development and progression of cancer $[39,40]$. Aberrant activation of NF-kB is observed in a 


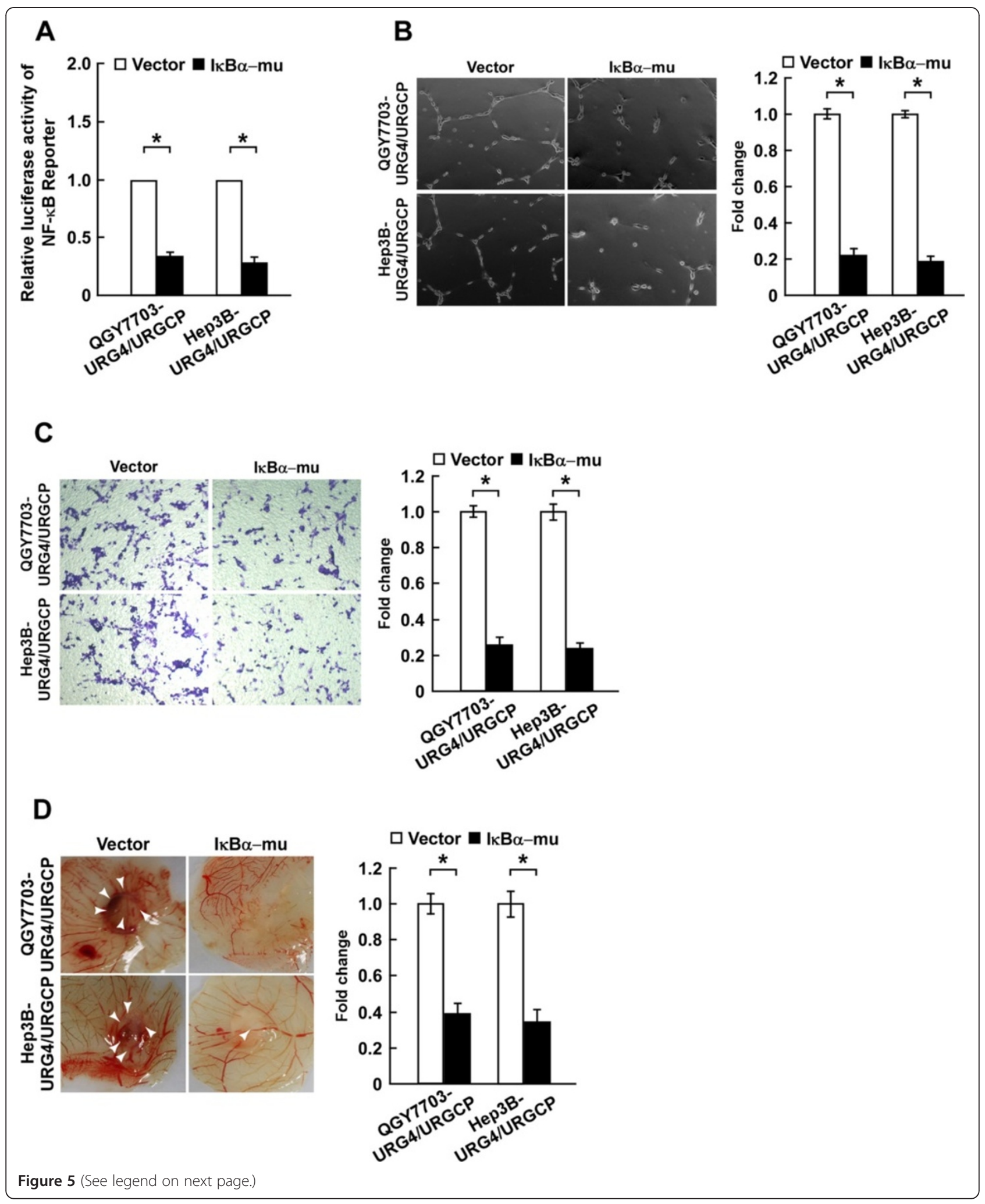


(See figure on previous page.)

Figure 5 URG4/URGCP enhances the angiogenic capacity of HCC cells via activating the NF-KB pathway. URG4/URGCP-overexpressing HCC cells were transfected with a non-degradable mutant IKBa protein, which acts as a specific NF-kB inhibitor. $\mathbf{A}$. Luciferase reporter assay of NF-kB transcriptional activity in the indicated cells. B. Representative images (left) and quantification (right) of tube-like structures formed by HUVECS on Matrigel-coated plates in the presence of CM from the indicated cells. C. Representative images (left) and quantification (right) of the number of migrated HUVEC cells in the Transwell migration assay after incubation in CM derived from the indicated cells. D. Representative images (left) and quantification (right) of neovessels formed in the CAM assay when stimulated by CM derived from the indicated cells. Data is mean \pm SD of three independent experiments; ${ }^{*} P<0.05$.

variety of tumor types. NF- $\mathrm{kB}$ mediates a range of biological processes in cancer cells by transcriptionally activating numerous target genes $[41,42]$. Activation of $\mathrm{NF}-\kappa \mathrm{B}$ signaling is negatively regulated by the I $\mathrm{kBs}$, which bind and sequester NF- $\mathrm{KB}$ in the cytoplasm in an inactive state. IKBs are phosphorylated by IKKs, which leads to ubiquitin-mediated degradation of the IKBs and consequently enables the release and translocation of NF-kB to the nucleus [43-45]. Consistent with these well-studied processes, the present study demonstrated that overexpression of URG4/URGCP upregulated the level of p-IKK and p-IKB $\alpha$ and ultimately enhanced the activation of NF- $\mathrm{kB}$. Additionally, when the cells overexpressing URG4/URGCP were transfected with the IкB $\alpha$ mutant, the capacity of CM from URG4/URGCP-overexpressing cells to enhance the angiogenic capacity of HCC cells was attenuated. These findings indicate that URG4/URGCP promotes the angiogenic capacity of HCC cells - at least in part - by activating the NF- $\kappa B /$ VEGFC signaling pathway.

Additionally, overexpression of URG4/URGCP upregulated a number of genes downstream of the NF- $\kappa B$ signaling pathway: TNF, $I L-6, I L-8$ and $M Y C$. TNF- $\alpha$ is well-recognized to promote angiogenesis and drive remodeling of blood vessels in vivo [46-48]; interleukin-6 increases the expression of VEGF and can promote angiogenesis [49-51]; IL-8 has been shown to play an important role in tumor angiogenesis [52]; and Myc plays an essential role in vasculogenesis and angiogenesis during the development and progression of various types of cancer [53-55]. It would be interesting to explore whether $T N F, I L-6, I L-8$ or $M Y C$ play a role in angiogenesis and disease progression in HCC, and explore the correlation between the expression of these genes and $V E G F C$. The regulatory mechanism by which upregulation of URG4/URGCP modulates the NF-kB/VEGFC pathway and enhances the angiogenic capacity of HCC cells remains to be elucidated and should be investigated further.

\section{Conclusion}

In conclusion, this study demonstrates that URG4/ URGCP is upregulated in HCC cell lines and enhances the angiogenic capacity of HCC cells via activation of the NF- $\mathrm{kB}$ signaling pathway. These results may provide new insight into the mechanisms that regulate angiogenesis in HCC; targeting URG4/URGCP may represent a promising therapeutic strategy for HCC.

\section{Additional files}

Additional file 1: Figure S1. Effect of URG4/URGCP on the angiogenic capacity of normal hepatic cell lines. A. Western blotting analysis of URG4/URGCP protein expression in LO2 and THLE3 cells transduced with either pMSCV-URG4/URGCP or the control vector pMSCV; a-Tubulin was used as a loading control. B. Representative images (left) and quantification (right) of tube-like structures formed by HUVECs cultured on Matrigel-coated plates in the presence of CM from the indicated cells. C. Representative images (left) and quantification (right) of the number of migrated HUVEC cells in the Transwell migration assay after incubation in CM derived from the indicated cells. D. Representative images (left) and quantification (right) of neovessels formed in the CAM assay when stimulated by CM derived from the indicated cells. E. Quantitative real-time PCR analysis of VEGFC mRNA expression in the indicated cells; transcript levels were normalized to GAPDH and expressed relative to the respective vector control cells. F. ELISA of VEGFC protein expression in the indicated cell supernatants. Data is mean \pm SD of three independent experiments; ${ }^{*} P<0.05$.

Additional file 2: Figure S2. Western blotting analysis of phosphorylated IKBa expression in the indicated cells; $\mathrm{a}$-Tubulin was used as a loading control.

\section{Abbreviations}

HCC: hepatocellular carcinoma; URG4: up-regulated gene-4; URGCP: upregulator of cell proliferation; NF-kB: nuclear factor kappa-light-chain-enhancer of activated B cells; VEGF: vascular endothelial growth factor; PDGF: plateletderived growth factor; FGFs: fibroblast growth factors; IKB: inhibitor of kappa B; IKK: IKB kinase; HUVEC: human umbilical vein endothelial cells; CAM: chicken chorioallantoic membrane; IL: interleukin; TNF-a: tumor necrosis factor alpha; HBV: hepatitis B virus; HCV: hepatitis C virus; HBxAg: hepatitis B virus X antigen; DMEM: Dulbecco's modified Eagle's medium; ATCC: American Type Culture Collection; FBS: fetal bovine serum; qRT-PCR: quantitive real-time RT-PCR; SD: standard deviation.

\section{Competing interests}

The authors have no competing interest to declare.

\section{Authors' contributions}

JYY, SDL and HPL participated in the design of study. SZX, BZ, RXH, ZRZ, $\mathrm{BHX}, \mathrm{CHH}$ and JSX performed experimental work. SZX, BZ, RXH, WCST and SQX performed the statistical analysis and helped to draft the manuscript. JYY, SDL and HPL provided administrative support and funded experiments. All authors read and approved the final manuscript.

\section{Acknowledgements}

This work was supported by the National Natural Science Foundation of China (grant numbers 30600156, 81071247), the Science and Technology Projects Foundation of Guangdong Province (grant numbers 2011B031800022, 2012B031800501) and Natural Science Foundation of Guangdong Province (grant numbers 2014A030313090, 2014A030313190). 


\section{Author details}

${ }^{1}$ Guangdong Provincial Key Laboratory of Gastroenterology, Department of Gastroenterology, Nanfang Hospital, Southern Medical University, Guangzhou 510000, P.R. China. ${ }^{2}$ Department of Gastroenterology, the First Affiliated Hospital of Sun Yat-sen University, Guangzhou 510000, P.R. China. ${ }^{3}$ Department of Internal Medicine, Baoan People's Hospital, Shenzhen 518101, P.R. China. ${ }^{4}$ Department of Medical Imaging, the First Affiliated Hospital of Sun Yat-sen University, Guangzhou 510000, P.R. China. ${ }^{5}$ Department of Oncology, the First Affiliated Hospital of Sun Yat-sen University, Guangzhou 510000, P.R. China. ${ }^{6}$ Center for Cancer and Inflammation Research, Institute of Integrated Bioinformedicine and Translational Science, Hong Kong Baptist University, Hong Kong, S.A.R., China. ${ }^{7}$ Department of Hepatobiliary Surgery, the First Affiliated Hospital of Gannan Medical University, Ganzhou 341000, P.R. China. ${ }^{8}$ Department of Biochemistry, University of Leicester, Leicester, UK.

\section{Received: 23 November 2014 Accepted: 27 April 2015}

\section{Published online: 07 May 2015}

\section{References}

1. Carmeliet P. Angiogenesis in life, disease and medicine. Nature. 2005:438(7070):932-6.

2. Folkman J. Role of angiogenesis in tumor growth and metastasis. Semin Oncol. 2002;29(6 Suppl 16):15-8.

3. Schneider BP, Miller KD. Angiogenesis of breast cancer. J Clin Oncol. 2005;23(8):1782-90.

4. Perol M, Arpin D. [Angiogenesis and lung cancer]. Bull Cancer. 2007;94 Spec No:S220-231.

5. Onishi M, Ichikawa T, Kurozumi K, Date I. Angiogenesis and invasion in glioma. Brain Tumor Pathol. 2011;28(1):13-24.

6. Leek RD. The prognostic role of angiogenesis in breast cancer. Anticancer Res. 2001;21(6B):4325-31.

7. Sato Y. Molecular diagnosis of tumor angiogenesis and anti-angiogenic cancer therapy. Int J Clin Oncol. 2003;8(4):200-6.

8. Weis SM, Cheresh DA. Tumor angiogenesis: molecular pathways and therapeutic targets. Nat Med. 2011;17(11):1359-70.

9. van Hinsbergh W, Collen A, Koolwijk P. Angiogenesis and anti-angiogenesis: perspectives for the treatment of solid tumors. Ann Oncol. 1999;10 Suppl 4:60-3.

10. Herbst RS, Fidler IJ. Angiogenesis and lung cancer: potential for therapy. Clin Cancer Res. 2000;6(12):4604-6.

11. Herbst RS, Onn A, Sandler A. Angiogenesis and lung cancer: prognostic and therapeutic implications. J Clin Oncol. 2005;23(14):3243-56.

12. Duarte IG, Bufkin BL, Pennington MF, Gal AA, Cohen C, Kosinski AS, et al. Angiogenesis as a predictor of survival after surgical resection for stage I non-small-cell lung cancer. J Thorac Cardiovasc Surg. 1998;115(3):652-8. discussion 658-659.

13. Pietras RJ, Weinberg OK. Antiangiogenic Steroids in Human Cancer Therapy. Evid Based Complement Alternat Med. 2005;2(1):49-57.

14. Folkman J. Endogenous angiogenesis inhibitors. APMIS. 2004;112(7-8):496-507.

15. Gyenge M, Amagase K, Kunimi S, Matsuoka R, Takeuchi K. Roles of proangiogenic and anti-angiogenic factors as well as matrix metalloproteinases in healing of NSAID-induced small intestinal ulcers in rats. Life Sci. 2013;93(12-14):441-7.

16. Marjon PL, Bobrovnikova-Marjon EV, Abcouwer SF. Expression of the pro-angiogenic factors vascular endothelial growth factor and interleukin-8/ CXCL8 by human breast carcinomas is responsive to nutrient deprivation and endoplasmic reticulum stress. Mol Cancer. 2004;3:4.

17. Hellberg C, Ostman A, Heldin CH. PDGF and vessel maturation. Recent Results Cancer Res. 2010;180:103-14.

18. Alfaro C, Suarez N, Gonzalez A, Solano S, Erro L, Dubrot J, et al. Influence of bevacizumab, sunitinib and sorafenib as single agents or in combination on the inhibitory effects of VEGF on human dendritic cell differentiation from monocytes. Br J Cancer. 2009;100(7):1111-9.

19. Thompson Coon J, Hoyle M, Green C, Liu Z, Welch K, Moxham T, et al. Bevacizumab, sorafenib tosylate, sunitinib and temsirolimus for renal cell carcinoma: a systematic review and economic evaluation. Health Technol Assess. 2010;14(2):1-184. iii-iv.

20. Willatt JM, Francis IR, Novelli PM, Vellody R, Pandya A, Krishnamurthy VN. Interventional therapies for hepatocellular carcinoma. Cancer Imaging. 2012;12:79-88.

21. Jemal A, Bray F, Center MM, Ferlay J, Ward E, Forman D. Global cancer statistics. CA Cancer J Clin. 2011;61(2):69-90.
22. Zhu AX, Duda DG, Sahani DV, Jain RK. HCC and angiogenesis: possible targets and future directions. Nat Rev Clin Oncol. 2011;8(5):292-301.

23. Finn RS, Zhu AX. Targeting angiogenesis in hepatocellular carcinoma: focus on VEGF and bevacizumab. Expert Rev Anticancer Ther. 2009;9(4):503-9.

24. Tufan NL, Lian Z, Liu J, Pan J, Arbuthnot P, Kew M, et al. Hepatitis Bx antigen stimulates expression of a novel cellular gene, URG4, that promotes hepatocellular growth and survival. Neoplasia. 2002;4(4):355-68.

25. Song J, Xie H, Lian Z, Yang G, Du R, Du Y, et al. Enhanced cell survival of gastric cancer cells by a novel gene URG4. Neoplasia. 2006;8(12):995-1002.

26. Xie C, Song LB, Wu JH, Li J, Yun JP, Lai JM, et al. Upregulator of cell proliferation predicts poor prognosis in hepatocellular carcinoma and contributes to hepatocarcinogenesis by downregulating FOXO3a. PLoS One 2012;7(7), e40607.

27. Li W, Zhou N. URG4 upregulation is associated with tumor growth and poor survival in epithelial ovarian cancer. Arch Gynecol Obstet. 2012;286(1):209-15.

28. Zhang L, Huang H, Hou T, Wu S, Huang Q, Song L, et al. URG4 overexpression is correlated with cervical cancer progression and poor prognosis in patients with early-stage cervical cancer. BMC Cancer. 2014;14:885

29. Hahn WC, Dessain SK, Brooks MW, King JE, Elenbaas B, Sabatini DM, et al Enumeration of the simian virus 40 early region elements necessary for human cell transformation. Mol Cell Biol. 2002;22(7):2111-23.

30. Jiang L, Song L, Wu J, Yang Y, Zhu X, Hu B, et al. Bmi-1 promotes glioma angiogenesis by activating NF-kappaB signaling. PLoS One. 2013;8(1), e55527.

31. Dai XL, Zhou SL, Qiu J, Liu YF, Hua H. Correlated expression of Fas, NF-kappaB, and VEGF-C in infiltrating ductal carcinoma of the breast. Eur J Gynaecol Oncol. 2012;33(6):633-9.

32. Jiang $L$, Lin C, Song $L$, Wu J, Chen B, Ying Z, et al. MicroRNA-30e* promotes human glioma cell invasiveness in an orthotopic xenotransplantation model by disrupting the NF-kappaB/lkappaBalpha negative feedback loop. J Clin Invest. 2012:122(1):33-47.

33. Vlachostergios PJ, Papandreou CN. The Bmi-1/NF-kappaB/NEGF story: another hint for proteasome involvement in glioma angiogenesis? J Cell Commun Signal. 2013;7(4):235-7.

34. Chen ZJ, Parent L, Maniatis T. Site-specific phosphorylation of IkappaBalpha by a novel ubiquitination-dependent protein kinase activity. Cell. 1996;84(6):853-62

35. Oymak Y, Dodurga Y, Turedi A, Yaman Y, Ozek G, Carti O, et al. Higher expression of the novel gene upregulated gene 4 in two acute lymphoblastic leukemia patients with poor prednisolone response. Acta Haematol. 2012;128(2):73-6.

36. Dodurga Y, Avci CB, Susluer SY, Satiroglu Tufan NL, Gunduz C. The expression of URGCP gene in prostate cancer cell lines: correlation with rapamycin. Mol Biol Rep. 2012;39(12):10173-7.

37. Dodurga Y, Oymak Y, Gunduz C, Satiroglu-Tufan NL, Vergin C, Cetingul N, et al. Leukemogenesis as a new approach to investigate the correlation between up regulated gene 4/upregulator of cell proliferation (URG4/ URGCP) and signal transduction genes in leukemia. Mol Biol Rep. 2013;40(4):3043-8.

38. Dodurga Y, Gundogdu G, Koc T, Yonguc GN, Kucukatay V, Satiroglu-Tufan NL. Expression of URG4/URGCP, Cyclin D1, BCl-2, and Bax genes in retinoic acid treated SH-SY5Y human neuroblastoma cells. Contemp Oncol. 2013;17(4):346-9.

39. Sen R, Baltimore D. Multiple nuclear factors interact with the immunoglobulin enhancer sequences. Cell. 1986;46(5):705-16.

40. Baldwin Jr AS. The NF-kappa B and I kappa B proteins: new discoveries and insights. Annu Rev Immunol. 1996;14:649-83.

41. Chen LF, Greene WC. Shaping the nuclear action of NF-kappaB. Nat Rev Mol Cell Biol. 2004;5(5):392-401.

42. Rayet B, Gelinas C. Aberrant rel/nfkb genes and activity in human cancer Oncogene. 1999;18(49):6938-47.

43. Sun SC, Ganchi PA, Ballard DW, Greene WC. NF-kappa B controls expression of inhibitor I kappa B alpha: evidence for an inducible autoregulatory pathway. Science. 1993;259(5103):1912-5.

44. Johnson C, Van Antwerp D, Hope TJ. An N-terminal nuclear export signal is required for the nucleocytoplasmic shuttling of IkappaBalpha. EMBO J. 1999;18(23):6682-93.

45. Huang T, Kudo N, Yoshida M, Miyamoto S. A nuclear export signal in the $\mathrm{N}$-terminal regulatory domain of IkappaBalpha controls cytoplasmic localization of inactive NF-kappaB/lkappaBalpha complexes. Proc Natl Acad Sci U S A. 2000;97(3):1014-9. 
46. Frater-Schroder M, Risau W, Hallmann R, Gautschi P, Bohlen P. Tumor necrosis factor type alpha, a potent inhibitor of endothelial cell growth in vitro, is angiogenic in vivo. Proc Natl Acad Sci U S A. 1987;84(15):5277-81.

47. Leibovich SJ, Polverini PJ, Shepard HM, Wiseman DM, Shively V, Nuseir N Macrophage-induced angiogenesis is mediated by tumour necrosis factoralpha. Nature. 1987;329(6140):630-2.

48. Baluk P, Yao LC, Feng J, Romano T, Jung SS, Schreiter JL, et al. TNF-alpha drives remodeling of blood vessels and lymphatics in sustained airway inflammation in mice. J Clin Invest. 2009;119(10):2954-64.

49. Huang SP, Wu MS, Shun CT, Wang HP, Lin MT, Kuo ML, et al. Interleukin-6 increases vascular endothelial growth factor and angiogenesis in gastric carcinoma. J Biomed Sci. 2004;11(4):517-27.

50. Fan Y, Ye J, Shen F, Zhu Y, Yeghiazarians Y, Zhu W, et al. Interleukin-6 stimulates circulating blood-derived endothelial progenitor cell angiogenesis in vitro. J Cereb Blood Flow Metab. 2008;28(1):90-8.

51. Cohen T, Nahari D, Cerem LW, Neufeld G, Levi BZ. Interleukin 6 induces the expression of vascular endothelial growth factor. J Biol Chem. 1996;271(2):736-41.

52. Li A, Dubey S, Varney ML, Dave BJ, Singh RK. IL-8 directly enhanced endothelial cell survival, proliferation, and matrix metalloproteinases production and regulated angiogenesis. J Immunol. 2003;170(6):3369-76.

53. Baudino TA, McKay C, Pendeville-Samain H, Nilsson JA, Maclean KH, White $\mathrm{EL}$, et al. c-Myc is essential for vasculogenesis and angiogenesis during development and tumor progression. Genes Dev. 2002;16(19):2530-43.

54. Knies-Bamforth UE, Fox SB, Poulsom R, Evan Gl, Harris AL. c-Myc interacts with hypoxia to induce angiogenesis in vivo by a vascular endothelial growth factor-dependent mechanism. Cancer Res. 2004;64(18):6563-70.

55. Chen C, Cai S, Wang G, Cao X, Yang X, Luo X, et al. c-Myc enhances colon cancer cell-mediated angiogenesis through the regulation of HIF-1alpha. Biochem Biophys Res Commun. 2013;430(2):505-11.

\section{Submit your next manuscript to BioMed Central and take full advantage of:}

- Convenient online submission

- Thorough peer review

- No space constraints or color figure charges

- Immediate publication on acceptance

- Inclusion in PubMed, CAS, Scopus and Google Scholar

- Research which is freely available for redistribution 